University of Rhode Island

DigitalCommons@URI

\title{
Health-Related and Sociodemographic Correlates of Meeting the Muscle Strengthening Exercise Recommendations in Middle-Aged and Older Adults with and without Disabilities
}

Shirit Kamil-Rosenberg

Mary L. Greaney

University of Rhode Island, mgreaney@uri.edu

Carol Ewing Garber

Follow this and additional works at: https://digitalcommons.uri.edu/htl_facpubs

The University of Rhode Island Faculty have made this article openly available.

Please let us know how Open Access to this research benefits you.

This is a pre-publication author manuscript of the final, published article.

Terms of Use

This article is made available under the terms and conditions applicable towards Open Access Policy Articles, as set forth in our Terms of Use.

\section{Citation/Publisher Attribution}

Kamil-Rosenberg, S., Greaney, M.L. \& Garber, C.E. Health-related and sociodemographic correlates of meeting the muscle strengthening exercise recommendations in middle-aged and older adults with and without disabilities. Sport Sci Health (2020). https://doi.org/10.1007/s11332-020-00674-y 
Health-related and sociodemographic correlates of meeting the muscle strengthening exercise recommendations in middle-aged and older adults with and without disabilities

Shirit Kamil-Rosenberg ${ }^{*}$, Mary L Greaney ${ }^{2}$, Carol Ewing Garber ${ }^{1}$

${ }^{1}$ Teachers College Columbia University, New York, NY, USA

${ }^{2}$ University of Rhode Island, Kingston, RI, USA

Address for Correspondence:

Shirit Kamil-Rosenberg, Ed.D.

VA Palo Alto Health Care System

3801 Miranda Ave

Building 4 C-150

Palo Alto, CA, 94304, USA

+1 (734) 834-1056

e-mail : shiritkamil@gmail.com 
Age, Disability, Muscle Strengthening Recommendations

\begin{abstract}
Purpose: To identify sociodemographic and health correlates of meeting the muscle strengthening (MS) exercise recommendations in middle-aged and older adults by disability status.
\end{abstract}

Methods: Respondents from the 2011 Behavioral Risk Factor Surveillance System were stratified by disability status (with disability, without disability), age [ages 45-64 (middle-aged), 65+ years of age (older adults)] and by whether they met MS recommendations (yes, no). Two logistic regression models were run to evaluate whether perceived health status and sociodemographic characteristics were associated with meeting the MS recommendations by disability status.

Results: The sample included 477,662. Middle-aged persons were $20 \%$ more likely than older adults to meet the MS recommendations. Persons with a disability were less likely to meet muscle strengthening recommendations compared with those without. Persons with a disability who reported having poor health were $\sim 65 \%$ less likely to meet the MS recommendation than those reporting excellent health. Furthermore, those with a disability and with one or more chronic diseases were nearly $40 \%$ less likely to meet the MS recommendation than no disability. Among respondents without disability, being Black and being a healthy weight or underweight increased the odds of meeting the MS recommendations.

Conclusions: Several health and sociodemographic factors were associated with not meeting MS recommendations. Persons with disability and poor health, had the lowest likelihood of participation. Studies are needed to understand whether improving MS exercise behavior may attenuate functional limitations associated with chronic diseases and aging. 
Age, Disability, Muscle Strengthening Recommendations

Keywords: Aging; BRFSS; Disability; Resistance training; Physical Activity 
Age, Disability, Muscle Strengthening Recommendations

\section{Introduction}

Current physical activity recommendations are that adults $18+$ years of age participate in muscle strengthening (MS) exercises that target all major muscle groups on two or three days per week $[1,2]$. Yet, less than a third of US adults meet this recommendation[3]. MS exercises increase muscular strength and endurance, enhance muscle mass and quality[4], promote bone health [5], and improve physical function [6]. The health benefits associated with MS exercises become increasingly important with age, as participating in MS exercise may reduce the risks of disability, falling, and extend independence [6-12]. Conversely, poor muscle strength can lead to a cascade of adverse events that result in increased all-cause mortality and chronic disease morbidity, mobility limitations, fear of falling, falls, and reduced quality of life — all of which can contribute to the loss of independence [6, 13-19].

People with physical disabilities often are less physically active than persons without physical disabilities [20-22]. This is concerning as insufficient physical activity can exacerbate the functional limitations associated with disabling conditions [2, 10, 23-26]. Moreover, people with disability and co-morbid chronic diseases are more likely to report less physical activity and more unhealthy behaviors that can lead to a cycle of worsening health and disability [27].

While having a disability is often considered a problem of particular concern among older adults, recent studies suggest there is an increasing incidence of disability in middle-aged adults [28]. Concurrently, the incidence of physical function impairments have plateaued in older adults while these impairments have multiplied in middle-aged adults [28]. Additionally, there is an escalating incidence of preventable chronic diseases, especially conditions in which insufficient exercise plays a contributory role in physical function impairments [28, 29]. There is 
Age, Disability, Muscle Strengthening Recommendations

a need to understand factors associated with meeting the MS recommendation, and to explore the associations between participation in MS exercises and health among middle-aged and older adults with and without disability to guide intervention development. The current study aimed to identify sociodemographic characteristics and health-related factors associated with meeting the MS recommendation in middle-aged and older adults with or without disability in a representative national sample of US adults. We hypothesized that factors associated with meeting the MS recommendation may differ between middle-aged and older adults. Additionally, we hypothesized that older adults and adults with disability will be less likely to meet the MS recommendation than middle-aged adults and adults without disability.

\section{Methods and Procedures}

The study sample was drawn from the 2011 Behavioral Risk Factor Surveillance System (BRFSS) [30]. The BRFSS is a random-digit dialing telephone-based health survey used to collect self-reported health information from adults $18+$ years of age in all 50 US states, the District of Columbia, and Puerto Rico [31]. It is the largest telephone health survey in the world, and states use the BRFSS data to identify emerging health problems, establish and track progress on meeting health objectives, and develop and evaluate public health policies and programs [31]. The study sample was limited to BRFSS respondents with complete data on MS exercise participation and variables used to determine disability status. Participants with missing data or who answered, "don't know" or "refused" to any of the examined socio-demographics and chronic disease questions were excluded from the respective analyses.

\section{Disability status}


Age, Disability, Muscle Strengthening Recommendations

Respondents were classified by disability status (with disability or without disability) using two BRFSS items consistent with the World Health Organization definitions of disability [32]. Respondents were considered to have a disability if they reported having an activity limitation due to physical, mental, or emotional problems; or they used special equipment (such as a mobility aid), or they met both criteria. Those who answered "no" to both questions were considered to be a person without disability.

\section{MS Exercise}

Respondents answered the following question assessing participation in MS exercises: "During the past month, how many times per week or per month did you do physical activities or exercises to STRENGTHEN your muscles? Count activities using your own body weight like yoga, sit-ups or push-ups and those using weight machines, free weights, or elastic bands." [30].

Responses options to this question were dichotomized as meeting or not meeting the MS recommendation. Respondents who answered $\geq 2$ times per week or $\geq 8$ times per month were

classified as meeting the MS recommendation, while respondents who reported participating 0 or 1 times per week (or $\leq 8$ times per month) were classified as not meeting the recommendation [30]. This classification scheme is consistent with current U.S. recommendation for MS exercise, which recommends participating in MS exercises 2 or more times per week [33].

\section{Sociodemographics}

Examined sociodemographic characteristics included age, sex, race/ethnicity (white nonHispanic, Black non-Hispanic, Hispanic or other), marital status (married, widowed, divorced, separated, never married, unmarried couple); education (high school or less, high school graduate, attended some college/technical school, or graduated college/technical school), and 
Age, Disability, Muscle Strengthening Recommendations

household income $(\leq \$ 15,000,>\$ 15,000 \leq \$ 25,000,>\$ 25,000 \leq \$ 35,000,>\$ 35,000$ to $\leq \$ 50,000$, $>\$ 50,000)$. As only a few respondents in the sample identified as Asian, Native Hawaiian or Other Pacific Islander, American Indian or Alaska Native, these categories were combined as "other" for analysis.

\section{Health-related measures}

\section{Self-Perceived Health Status:}

Respondents reported their perceived health status by answering one question that asked them to rate their health (excellent, very good, good, fair, poor.) This question, derived from the SF-36, is predictive of morbidity and mortality, and of the composite physical and mental health scores of the SF-36 [34].

\section{Chronic Disease Status:}

Respondents indicated whether or not a health care provider had told them they had asthma, cardiovascular diseases (stroke or coronary heart disease), arthritis, and diabetes. Participants also reported their height and weight, which was used to calculate body mass index (BMI); underweight $\left(<18.5 \mathrm{~kg} / \mathrm{m}^{2}\right)$, healthy weight $\left(18.5-24.9 \mathrm{~kg} / \mathrm{m}^{2}\right)$, overweight $(25-29.9 \mathrm{~kg} /$ $\left.\mathrm{m}^{2}\right)$, or obese $\left(\geq 30 \mathrm{~kg} / \mathrm{m}^{2}\right)$ [35].

\section{Statistical Analyses}

The analyses used for this study used a weighing methodology by the Centers for Disease Control (CDC) known as iterative proportional fitting or raking. This method, applied to the raw data, adjusts for each variable individually in a series of data processing-intensive iterations and allows for the incorporation of data obtained from both landline and cellular telephones. Each 
Age, Disability, Muscle Strengthening Recommendations

variable in the weighting process is included in the model, and the weights are adjusted until the sample weights are representative of the population. Raking does not require demographic information for small geographic areas, and allows variables to be included in the weighting process, which increases the representativeness of estimates[31].

\section{Descriptive Analyses}

Descriptive characteristics of the sample were calculated as means and standard deviations for continuous variables, while categorical variables were reported as frequencies and percentages. Sociodemographic characteristics were evaluated by disability status and age groups using crosstabs analyses.

\section{Logistic Regression Analyses}

Two enter method logistic regression models were created to examine potential sociodemographic and health-related correlates of meeting the MS recommendation, stratified by disability status. Prior to conducting the logistic regression analyses, biserial correlation analyses assessed the potential of multicollinearity among the independent variables. Correlations greater than $\mathrm{r}=0.8$ were considered to be indicative of multicollinearity and, as a result, income was excluded from the analysis due to collinearity with education. In these models, chronic disease status was dichotomized as the presence one or more chronic disease (yes, no). All analyses were executed using SPSS Statistics Software (Windows version 24. IBM, Inc., Armonk, NY, USA).

\section{Results}


Age, Disability, Muscle Strengthening Recommendations

The sample included 477,662 adults ages 45 years and older. Table 1a shows the sociodemographic and health-related characteristics stratified by MS recommendations. Respondents who more often met MS recommendation were males, those without disability. those with a healthy weight, middle-aged, better educated and married were more likely to meet the MS recommendation $(\mathrm{p}<0.001)$.

Among those who met the MS recommendation, regardless of disability status, more men, middle-aged, married persons, those with higher incomes and greater education more often met the MS recommendation. The majority of persons with disability who met the MS recommendation were of healthy weight or underweight, and reported their health to be good, very good, or excellent (see Table $1 b$ ).

Respondents with one or more chronic diseases were 1.5 (1.58: 1.20-2.08 95\%CI) times more likely to meet MS recommendations (Table 2). Further, people with disability were only slightly more likely to meet the MS recommendation than people without disability. However, those with obesity were less likely to meet the MS recommendation. Goodness of fit index reported about a $9 \%$ of the variance in the outcome (Table 2 and 3 ).

Table 3 presents the two logistic regression models that evaluated the correlates of meeting the MS recommendation by disability status. Model one was limited to persons with disability while Model 2 included all respondents. In model 1, men were nearly 25\% (1.24: 1.16$1.3295 \% \mathrm{CI}$ ) more likely to meet the MS recommendations than women. Additionally, middleaged with more education were more likely to meet the MS recommendation. In this model, individuals who were a healthy weight or underweight were almost twice as likely to meet in MS recommendation than individuals with obesity. Persons identifying as Black were about $25 \%$ 
Age, Disability, Muscle Strengthening Recommendations

more likely to meet the MS recommendation than those identifying as white. Divorced respondents were nearly $15 \%$ less likely to meet MS recommendations than married respondents, while those who were widowed were slightly more likely to meet the MS recommendations.

\section{Discussion}

A worrisome trend is the escalation in the number of middle-aged adults who have a disability, mainly resulting physical function impairments [28]. The primary contributory factors to the increasing incidence of disability in middle-aged adults are preventable chronic diseases (e.g., Type 2 diabetes mellitus, cardiovascular diseases, obesity, conditions such as arthritis) in which physical activity, especially MS exercise, can help maintain physical function and improve overall health [28]. Interestingly, in the full analytic sample (including those with and without disability), being middle-aged (vs. older age), or male were associated with meeting MS recommendation, while higher BMI was associated with a lower likelihood of sufficient participation in MS exercises.

Among persons with disability, respondents with a healthy body weight or underweight were about 1.5 to 1.8 times more likely to meet the MS recommendation than persons with obesity. Additionally, those with disability who were married, earned a higher income, and had a higher education level were more likely to meet the MS recommendations.

Race/ethnicity was only associated with meeting the MS recommendation among people without disability, with those identifying as Black being about $25 \%$ more likely to engage in MS recommendations than whites. Several variables were associated with a lower likelihood of participation in meeting MS recommendation, which were similar among people with or without a disability. This included having less than excellent health, having one or more chronic disease 
Age, Disability, Muscle Strengthening Recommendations

(those without disability), divorced, and having an educational attainment of less than college graduation.

Determining who engages in sufficient MS exercise is important because MS exercises have considerable benefits for health, function, fitness, and longevity [13-17]. Previous population-based studies focused on the prevalence of MS exercise participation in select populations such as those with lower back pain, neuromuscular, and musculoskeletal diseases, however in both meta-analyses, there were either no benefits or benefits with further investigations needed, indicating that more studies need to explore this topic $[36,37]$. The present study extends this limited research on MS exercise participation in select samples which found that participation in MS exercise are associated with overall function and quality of life in middle-aged and older adults $[15,38,39]$ although few of these studies examined the association with disability. Results of the present study are similar to prior studies that have found that people who identify as having a disability participate in less aerobic physical activity and those who are physically active [40]. Our previous research evaluated the associations between chronic disease and disability prevalence and meeting aerobic and MS recommendations in younger, middle aged and older adults[41]. This current study further extends the understanding about MS participation and shows that in the general US adult population engagement in MS exercise is low, and even lower in those with a disability compared to those without disability.

Previous studies report a strong association with aerobic physical activity and health status among adults [7, 39, 42], where persons who perceived themselves as being in excellent or good health were more likely to meet the recommendations for aerobic physical activity compared with those in who perceive their health as being poor. Although not focused on MS exercises, Garber et al. observed that rarely feeling healthy or full of energy was a strong 
Age, Disability, Muscle Strengthening Recommendations

correlate of being in the earlier stages of change (precontemplation, contemplation in preparation) for physical activity, which is a surrogate indicator of participation in insufficient aerobic physical activity [39]. People with poorer health may be less likely to participate in MS exercises as well. In the current study, we found that those who perceived themselves as being in poor health were nearly $60 \%$ less likely to meet the MS recommendation than those with excellent health. Moreover, people with a disability often report poorer health status than persons without disability and may have additional barriers to physical activity participation compared with people without disability, including pain and fatigue [43]. Additionally, in the total sample, (table 2 and 3), chronic disease status was associated with either greater (table 2) or lesser participation (table 3). This is intriguing as it suggests that the presence of chronic disease is may be a barrier and facilitator of exercise participation. Similar findings were reported in a study of stages of behavior change for exercise in Rhode Island adults where having a health limitation was associated with both being in the precontemplation and being in the action stage for exercise[39]. These results of our study and that of Garber et al suggests that there may be complex interactions between physical activity behavior and health status, perceptions of health, perceived functional limitation that are worthy of further study.

Our study contributes to the existing literature by identifying health-related correlates associated with meeting the MS recommendations with self-reported health status in both middle-aged and older adults across disability status. Middle-aged adults with or without a disability in our study were more likely to meet the MS recommendations than were older adults. Vezina et al (2014) reported similar rates of MS exercise participation in a general adult population: however, they did not look for differences in MS exercise participation by disability status. Middle-aged persons are of working age and the potential economic and long-term impact 
Age, Disability, Muscle Strengthening Recommendations

of disabling conditions could be substantial, particularly as these individuals age. The primary contributory factors to the increasing incidence of disability in middle-aged adults are preventable chronic diseases (such as diabetes, cardiovascular diseases, and obesity, or conditions such as arthritis) in which physical activity, especially MS exercise, can help maintain physical function and improve overall health [28], and so there is good reason to think that promoting physical activity might be part of an effective interventions [28, 44].

The current study determined that self-reported health status, age, sex, and education were associated with meeting the MS recommendations, irrespective of disability status. It is well known that physical activity is important for the health of all adults, including people with disability $[45,46]$. However, because there are limited studies examining physical activity among people with disability, our results are important as they help to identify subpopulations who are in more urgent need of intervention and potential behavioral targets for interventions. Further research examining how sociodemographic characteristics and health status may affect MS exercise participation in people with disability is needed to guide the development of effective interventions to promote the adoption and maintenance of participating in MS exercises.

\section{Limitations:}

This study has several limitations. The BRFSS sampling methods include only noninstitutionalized adults with telephones and adults willing or able to answer the telephone thus it likely underestimates the prevalence of disability in the population, and possibly disproportionately in older adults [8, 47]. This study relied on self-report measures [38]. Furthermore, this was a cross-sectional study, which does not allow for causal inferences. 
Age, Disability, Muscle Strengthening Recommendations

Nonetheless, surveillance studies study individuals' perception of their physical activity levels (compared to objectively measured physical activity) and strongly predict mortality, even though it can lead to over estimation of physical activity [48]. The definition of disability was based on self-reporting of limitations due to physical, mental or emotional problems, and the reported use of special equipment, and so it was a broad definition of functional limitations. Nonetheless, due to its breadth, it made it difficult to identify all of the specific limitations of the respondents [38]. The BRFSS items did not allow us to determine what type of disability respondents have, and so the types and causes of disability were combined together into one variable, as opposed to separating different types of disabilities in BRFSS. By stratifying different types of disability, there could be different interpretations of the prevalence of meeting the MS strengthening exercise recommendations and the associations between disability and MS participation. The recommendations for MS strengthening exercises address exercise dose by including the elements of frequency and intensity, but the BRFSS question only addresses frequency and does not assess intensity. It is possible that the self-report over-estimated the proportion of respondents who met MS recommendations. The missing data in some instances (i.e., sociodemographics and chronic diseases) was greater than $5 \%$ of the data, and is not likely missing completely at random. Therefore, results apply only to the subset of the population who would answer these types of questions, and not the population as a whole from which the sample was drawn. Moreover, the chronic disease questions in the BRFSS asked if the individual had ever been told by a doctor or health professional they had been diagnosed with a disease, and this probably resulted in under-reporting of the actual presence of disease.

\section{Conclusions}

In this study, we identified the correlates of MS participation among people with and 
without disability. Regardless of disability status, middle-aged respondents were more likely than older adults to meet MS recommendations. Additionally, regardless of disability status, people with healthy weight, more education, and excellent health more often met the MS recommendation. Persons with disability and those who had a chronic disease(s) were less likely to meet the MS recommendation compared to those without disability. Trends in physical function impairments support the urgency of addressing increasing disability and the associated public health implications in adults, especially when interventions may attenuate these trends. Further studies are needed to understand more fully the activity choices of persons with disability and self-perceived health status, and whether improving MS exercise behavior may attenuate functional limitations associated with chronic diseases and aging.

\section{Disclosure statement}

The authors report no conflicts of interest. 


\section{References}

1. Garber CE, Blissmer B, Deschenes MR, Franklin BA, Lamonte MJ, Lee IM, Nieman DC, Swain DP, American College of Sports M: American College of Sports Medicine position stand. Quantity and quality of exercise for developing and maintaining cardiorespiratory, musculoskeletal, and neuromotor fitness in apparently healthy adults: guidance for prescribing exercise. Med Sci Sports Exerc 2011, 43(7):13341359.

2. U.S. Department of Health and Human Services: 2018 Physical Activity Guidelines Advisory Committee Scientific Report. In., 2nd edn. Washington, DC: U.S. Department of Health and Human Services; 2018.

3. Centers for Disease $\mathrm{C}$, Prevention: Adult participation in aerobic and musclestrengthening physical activities--United States, 2011. MMWR Morb Mortal Wkly Rep 2013, 62(17):326-330.

4. Phillips SM, Winett RA: Uncomplicated resistance training and health-related outcomes: evidence for a public health mandate. Curr Sports Med Rep 2010, 9(4):208213.

5. Beck BR, Daly RM, Singh MA, Taaffe DR: Exercise and Sports Science Australia (ESSA) position statement on exercise prescription for the prevention and management of osteoporosis. J Sci Med Sport 2017, 20(5):438-445.

6. Ciolac EG: Exercise training as a preventive tool for age-related disorders: a brief review. Clinics (Sao Paulo) 2013, 68(5):710-717.

7. Boslaugh SE, Andresen EM: Correlates of physical activity for adults with disability. Preventing chronic disease 2006, 3(3):A78.

8. Thompson WW, Zack MM, Krahn GL, Andresen EM, Barile JP: Health-related quality of life among older adults with and without functional limitations. American journal of public health 2012, 102(3):496-502.

9. Hirschfeld HP, Kinsella R, Duque G: Osteosarcopenia: where bone, muscle, and fat collide. Osteoporos Int 2017, 28(10):2781-2790.

10. Ciolac EG, Rodrigues-da-Silva JM: Resistance Training as a Tool for Preventing and Treating Musculoskeletal Disorders. Sports Med 2016, 46(9):1239-1248.

11. Westcott WL: Resistance training is medicine: effects of strength training on health. Curr Sports Med Rep 2012, 11(4):209-216.

12. Pollock ML, Franklin BA, Balady GJ, Chaitman BL, Fleg JL, Fletcher B, Limacher M, Pina IL, Stein RA, Williams M et al: AHA Science Advisory. Resistance exercise in individuals with and without cardiovascular disease: benefits, rationale, safety, and prescription: An advisory from the Committee on Exercise, Rehabilitation, and Prevention, Council on Clinical Cardiology, American Heart Association; Position paper endorsed by the American College of Sports Medicine. Circulation 2000, 101(7):828-833.

13. Bauman A, Merom D, Bull FC, Buchner DM, Fiatarone Singh MA: Updating the Evidence for Physical Activity: Summative Reviews of the Epidemiological Evidence, Prevalence, and Interventions to Promote "Active Aging". Gerontologist 2016, 56 Suppl 2:S268-280.

14. Looker AC, Wang CY: Prevalence of reduced muscle strength in older U.S. adults: United States, 2011-2012. NCHS Data Brief 2015(179):1-8. 
15. Vezina JW, Der Ananian CA, Greenberg E, Kurka J: Sociodemographic correlates of meeting US Department of Health and Human Services muscle strengthening recommendations in middle-aged and older adults. Preventing chronic disease 2014, 11:E162.

16. Benichou O, Lord SR: Rationale for Strengthening Muscle to Prevent Falls and Fractures: A Review of the Evidence. Calcified tissue international 2016, 98(6):531545.

17. Stamatakis E, Lee IM, Bennie J, Freeston J, Hamer M, O'Donovan G, Ding D, Bauman A, Mavros Y: Does Strength-Promoting Exercise Confer Unique Health Benefits? A Pooled Analysis of Data on 11 Population Cohorts With All-Cause, Cancer, and Cardiovascular Mortality Endpoints. Am J Epidemiol 2018, 187(5):1102-1112.

18. Li R, Xia J, Zhang XI, Gathirua-Mwangi WG, Guo J, Li Y, McKenzie S, Song Y: Associations of Muscle Mass and Strength with All-Cause Mortality among US Older Adults. Med Sci Sports Exerc 2018, 50(3):458-467.

19. Trombetti A, Reid KF, Hars M, Herrmann FR, Pasha E, Phillips EM, Fielding RA: Ageassociated declines in muscle mass, strength, power, and physical performance: impact on fear of falling and quality of life. Osteoporos Int 2016, 27(2):463-471.

20. Santiago M, Coyle C: Leisure-time physical activity and secondary conditions in women with physical disabilities. Disability and rehabilitation 2004, 26(8):485-494.

21. Healthy People 2020 [http://www.healthypeople.gov/2020/topicsobjectives2020/overview.aspx?topicid=9]

22. Rimmer JH, Rowland, J. L. : Health promotion for people with disabilities: Implications for empowering the person and promoting disability-friendly environments. American journal of lifestyle medicine 2008, 2(5):409-420.

23. van der Ploeg HP, van der Beek AJ, van der Woude LH, van Mechelen W: Physical activity for people with a disability: a conceptual model. Sports Medicine 2004, 34(10):639-649.

24. Weil E, Wachterman M, McCarthy EP, Davis RB, O'Day B, Iezzoni LI, Wee CC: Obesity among adults with disabling conditions. JAMA 2002, 288(10):1265-1268.

25. Nantel J, Mathieu ME, Prince F: Physical activity and obesity: biomechanical and physiological key concepts. Journal of obesity 2011, 2011:650230.

26. Zhao G, Ford ES, Li C, Crews JE, Mokdad AH: Disability and its correlates with chronic morbidities among U.S. adults aged 50-<65 years. Preventive medicine 2009, 48(2):117-121.

27. Froehlich-Grobe K, Jones D, Businelle MS, Kendzor DE, Balasubramanian BA: Impact of disability and chronic conditions on health. Disabil Health J 2016.

28. Martin LG, Schoeni RF: Trends in disability and related chronic conditions among the forty-and-over population: 1997-2010. Disabil Health J 2014, 7(1 Suppl):S4-14.

29. Martin LG, Freedman VA, Schoeni RF, Andreski PM: Trends in disability and related chronic conditions among people ages fifty to sixty-four. Health affairs 2010, 29(4):725-731.

30. Center for Disease Control and Prevention: Behavioral Risk Factor Surveillance System Survey Data. In., vol. 2012. Atlanta, GA: U.S. Department of Health and Human Services, Centers for Disease Control and Prevention; 2011. 
31. Centers for Disease C, Prevention: Methodologic changes in the Behavioral Risk Factor Surveillance System in 2011 and potential effects on prevalence estimates. MMWR Morb Mortal Wkly Rep 2012, 61(22):410-413.

32. World Health Organization.: International classification of functioning, disability and health : ICF. Geneva: World Health Organization; 2001.

33. U.S. Department of Health and Human Services, Public Health Service, Centers for Disease: 2008 Physical Activity Guidelines for Americans. In. Edited by Services UDoHaH. Washington, DC; 2008.

34. McHorney CA, Ware JE, Jr., Lu JF, Sherbourne CD: The MOS 36-item Short-Form Health Survey (SF-36): III. Tests of data quality, scaling assumptions, and reliability across diverse patient groups. Medical care 1994, 32(1):40-66.

35. National Institutes of Health National Heart Lung and Blood Institute: Clinical guidelines on the identification, evaluation, and treatment of overweight and obesity in adults: the evidence report. In. Edited by National Institutes of Health NH, Lung, and Blood Institute. Rockville, MD: National Institutes of Health, National Heart, Lung, and Blood Institute; 1998.

36. Charron S, McKay KA, Tremlett H: Physical activity and disability outcomes in multiple sclerosis: A systematic review (2011-2016). Mult Scler Relat Disord 2018, 20:169-177.

37. Magni NE, McNair PJ, Rice DA: The effects of resistance training on muscle strength, joint pain, and hand function in individuals with hand osteoarthritis: a systematic review and meta-analysis. Arthritis Res Ther 2017, 19(1):131.

38. Brown DR, Yore MM, Ham SA, Macera CA: Physical activity among adults $>$ or=50 yr with and without disabilities, BRFSS 2001. Medicine \& Science in Sports \& Exercise 2005, 37(4):620-629.

39. Garber CE, Allsworth JE, Marcus BH, Hesser J, Lapane KL: Correlates of the stages of change for physical activity in a population survey. American journal of public health 2008, 98(5):897-904.

40. Rimmer JH, Marques, A.C.: Physical activity for people with disabilities. Lancet 2012:193-195.

41. Kamil-Rosenberg S, Greaney ML, Hochman T, Garber CE: How Do Physical Activity and Health Vary Among Younger, Middle-Aged, and Older Adults With and Without Disability? J Aging Phys Act 2019, 27(2):234-241.

42. Bize R, Johnson JA, Plotnikoff RC: Physical activity level and health-related quality of life in the general adult population: a systematic review. Preventive medicine 2007, 45(6):401-415.

43. Patterson BJ, Doucette WR, Lindgren SD, Chrischilles EA: Living with disability: patterns of health problems and symptom mediation of health consequences. Disabil Health J 2012, 5(3):151-158.

44. Bauer UE, Briss PA, Goodman RA, Bowman BA: Prevention of chronic disease in the 21st century: elimination of the leading preventable causes of premature death and disability in the USA. Lancet 2014, 384(9937):45-52.

45. US Department of Health and Human Services: 2008 Physical Activity Guidelines for Americans. In. Washington, D.C.: U.S. Department of Health and Human Services; 2008. 
46. American College of Sports M, Chodzko-Zajko WJ, Proctor DN, Fiatarone Singh MA, Minson CT, Nigg CR, Salem GJ, Skinner JS: American College of Sports Medicine position stand. Exercise and physical activity for older adults. Med Sci Sports Exerc 2009, 41(7):1510-1530.

47. Okoro CA, Hootman JM, Strine TW, Balluz LS, Mokdad AH: Disability, arthritis, and body weight among adults 45 years and older. Obesity research 2004, 12(5):854-861.

48. Zahrt $\mathrm{OH}, \mathrm{Crum} \mathrm{AJ}$ : Perceived physical activity and mortality: Evidence from three nationally representative U.S. samples. Health Psychol 2017, 36(11):1017-1025.

Table 1a: Descriptive Characteristics of BRFSS Respondents by Meeting MS Recommendations 
Age, Disability, Muscle Strengthening Recommendations

$(n=477,662 ;$ missing data $=28,803(5.7 \%))$.

\begin{tabular}{|c|c|c|c|}
\hline & & \multicolumn{2}{|c|}{ Met MS recommendations } \\
\hline \multicolumn{2}{|l|}{ Variable } & Yes $(n=353,420)(\%)$ & No $(n=124,242)(\%)$ \\
\hline \multirow[t]{2}{*}{ Sex } & Male & 45.2 & 37.1 \\
\hline & Female & 54.8 & 62.9 \\
\hline \multirow[t]{2}{*}{ Age } & 45-64 years (middle-aged) & 60.6 & 55.5 \\
\hline & $65+$ years older adults & 39.4 & 44.5 \\
\hline \multirow[t]{2}{*}{ Disability status } & Persons with Disability & 25.6 & 32.8 \\
\hline & Persons without Disability & 74.4 & 67.2 \\
\hline \multirow[t]{5}{*}{ Income } & Less than $\$ 15,000$ & 8.8 & 13.9 \\
\hline & $\$ 15,000$ to less than $\$ 25,000$ & 14.0 & 19.5 \\
\hline & $\$ 25,000$ to less than $\$ 35,000$ & 10.4 & 12.5 \\
\hline & $\$ 35,000$ to less than $\$ 50,000$ & 14.3 & 15.2 \\
\hline & $\$ 50,000$ or more & 52.5 & 38.9 \\
\hline \multirow[t]{4}{*}{ Education } & Did not graduate High School & 5.2 & 10.2 \\
\hline & HS Graduate & 22.2 & 31.7 \\
\hline & Attended College/Technical & 27.2 & 27.1 \\
\hline & Graduated College/Technical & 45.4 & 31.0 \\
\hline \multirow[t]{6}{*}{ Marital Status } & Married & 54.5 & 53.2 \\
\hline & Divorced & 10.0 & 15.0 \\
\hline & Widowed & 13.5 & 14.4 \\
\hline & Separated & 1.9 & 2.2 \\
\hline & Never Married & 17.3 & 12.7 \\
\hline & Member of an Unmarried Couple & 2.9 & 2.4 \\
\hline \multirow[t]{4}{*}{ Race } & White - Non-Hispanic & 80.9 & 79.7 \\
\hline & Black - Non-Hispanic & 7.8 & 8.2 \\
\hline & Hispanic & 6.7 & 8.1 \\
\hline & Other & 4.6 & 4.0 \\
\hline Asthma & Yes & 12.3 & 13.1 \\
\hline
\end{tabular}


Age, Disability, Muscle Strengthening Recommendations

\begin{tabular}{|l|l|c|c|}
\hline Past Stroke & Yes & 3 & 4.4 \\
\hline $\begin{array}{l}\text { Past Angina or } \\
\text { Coronary Disease }\end{array}$ & Yes & 4.5 & 6.5 \\
\hline \multirow{2}{*}{ Arthritis } & Yes & 35.3 & 28.4 \\
\hline \multirow{2}{*}{ Diabetes } & Yes & 8.1 & 13.8 \\
\hline \multirow{5}{*}{ BMI } & Underweight need to define categories & 1.7 & 1.7 \\
\cline { 2 - 4 } & Normal & 41.6 & 31.4 \\
\cline { 2 - 4 } & Overweight & 36.9 & 36.1 \\
\cline { 2 - 4 } & Obese & 30.9 & 19.9 \\
\hline \multirow{3}{*}{ Health Status } & Excellent & 24.3 & 12.5 \\
\cline { 2 - 4 } & Very Good & 35.1 & 29.3 \\
\cline { 2 - 4 } & Good & 26.1 & 33.0 \\
\cline { 2 - 4 } & Fair & 10.3 & 17.2 \\
\cline { 2 - 4 } & Poor & 4.2 & 8.1 \\
\hline
\end{tabular}

Note: Table includes some missing values due to responses that were missing, refused and unknown. P value refers to crosstabs analysis for each variable categories by aerobic categories. Each row chi-square is statistically significant $(\mathrm{p}<0.01)$. 
Table 1b: Descriptive Characteristics of a Representative National Sample of Disability and MS Recommendations by Meeting MS Recommendation

\begin{tabular}{|c|c|c|c|c|c|}
\hline \multirow[b]{2}{*}{ Variable } & & \multicolumn{2}{|c|}{ Persons with Disability } & \multicolumn{2}{|c|}{ Persons without Disability } \\
\hline & & $\begin{array}{c}\text { Meeting MS } \\
\text { Recommendation } \\
(\%)\end{array}$ & $\begin{array}{c}\text { Not Meeting MS } \\
\text { Recommendation } \\
(\%)\end{array}$ & $\begin{array}{c}\text { Meeting MS } \\
\text { Recommendation } \\
(\%)\end{array}$ & $\begin{array}{c}\text { Not Meeting MS } \\
\text { Recommendation } \\
(\%)\end{array}$ \\
\hline \multirow{2}{*}{$\begin{array}{l}\text { Sex } \\
n=472,773(93.3 \%) \\
\text { missing }=33,694 \\
(6.7 \%)\end{array}$} & Male & 24.6 & 75.4 & 32.2 & 67.8 \\
\hline & Female & 19.9 & 80.1 & 25.2 & 74.8 \\
\hline \multirow{2}{*}{$\begin{array}{l}\text { Age } \\
\mathrm{n}=344,288(93.5 \%) \\
\text { missing=24,002 } \\
(6.5 \%)\end{array}$} & $45-64$ & 21.6 & 78.4 & 27.0 & 73.0 \\
\hline & 65 and older & 19.5 & 80.5 & 23.0 & 77.0 \\
\hline \multirow{5}{*}{$\begin{array}{l}\text { Income } \\
\mathrm{n}=294,723(80 \%) \\
\text { missing }=73,567 \\
(20 \%)\end{array}$} & Less than $\$ 15,000$ & 15.7 & 84.3 & 16.2 & 83.8 \\
\hline & $\begin{array}{l}\$ 15,000 \text { to less than } \\
\$ 25,000\end{array}$ & 17.3 & 82.7 & 18.4 & 81.6 \\
\hline & $\begin{array}{l}\$ 25,000 \text { to less than } \\
\$ 35,000\end{array}$ & 19.5 & 80.5 & 21.0 & 79.0 \\
\hline & $\begin{array}{l}\$ 35,000 \text { to less than } \\
\$ 50,000\end{array}$ & 21.8 & 78.2 & 23.5 & 76.5 \\
\hline & $\$ 50,000$ or more & 28.2 & 71.8 & 31.9 & 68.1 \\
\hline \multirow{4}{*}{$\begin{array}{l}\text { Education } \\
\mathrm{n}=471.799(93.2 \%) \\
\text { missing }=34,668 \\
(6.8 \%)\end{array}$} & High School or less & 13.0 & 87.0 & 17.0 & 83.0 \\
\hline & HS Graduate & 16.6 & 83.4 & 21.3 & 78.7 \\
\hline & $\begin{array}{l}\text { Attended some } \\
\text { College/Technical }\end{array}$ & 22.3 & 77.7 & 27.9 & 72.1 \\
\hline & $\begin{array}{l}\text { Graduated } \\
\text { College/Technical }\end{array}$ & 30.2 & 69.8 & 35.2 & 64.8 \\
\hline \multirow{6}{*}{$\begin{array}{l}\text { Marital Status } \\
\mathrm{n}=470,916(93 \%) \\
\text { missing }=35,551(7 \%)\end{array}$} & Married & 22.6 & 77.4 & 27.8 & 72.2 \\
\hline & Widowed & 20.7 & 79.3 & 27.4 & 72.6 \\
\hline & Divorced & 17.5 & 82.5 & 20.1 & 79.9 \\
\hline & Separated & 19.9 & 80.1 & 25.5 & 74.5 \\
\hline & Never Married & 25.8 & 74.2 & 34.6 & 65.4 \\
\hline & $\begin{array}{l}\text { A Member of an } \\
\text { Unmarried Couple }\end{array}$ & 25.7 & 74.3 & 30.6 & 69.4 \\
\hline \multirow{4}{*}{$\begin{array}{l}\text { Race/ethnicity } \\
\mathrm{n}=459,183(90.7 \%) \\
\text { missing=47,284 } \\
(90.3 \%)\end{array}$} & $\begin{array}{l}\text { White - Non- } \\
\text { Hispanic }\end{array}$ & 21.9 & 78.1 & 28.2 & 71.8 \\
\hline & $\begin{array}{l}\text { Black - Non- } \\
\text { Hispanic }\end{array}$ & 19.7 & 80.3 & 27.6 & 72.4 \\
\hline & Hispanic & 23.0 & 77.0 & 23.7 & 76.3 \\
\hline & Other & 28.6 & 71.4 & 30.5 & 69.5 \\
\hline
\end{tabular}


Age, Disability, Muscle Strengthening Recommendations

\begin{tabular}{|c|c|c|c|c|c|}
\hline $\begin{array}{l}\text { Asthma } \\
\mathrm{n}=60,888(28.6 \%)\end{array}$ & Yes & 20.7 & 79.3 & 28.7 & 71.3 \\
\hline $\begin{array}{l}\text { Stroke } \\
\mathrm{n}=18,903(10.5 \%)\end{array}$ & Yes & 18.7 & 81.3 & 20.5 & 79.5 \\
\hline $\begin{array}{l}\text { Coronary Disease } \\
n=28,303(15.3 \%)\end{array}$ & Yes & 19.5 & 80.5 & 22.3 & 77.7 \\
\hline $\begin{array}{l}\text { Arthritis } \\
\mathrm{n}=157,784(54.8 \%)\end{array}$ & Yes & 20.5 & 79.5 & 24.1 & 75.9 \\
\hline $\begin{array}{l}\text { Diabetes } \\
\mathrm{n}=58,129(29.4 \%)\end{array}$ & Yes & 16.6 & 83.4 & 17.4 & 82.6 \\
\hline \multirow{4}{*}{$\begin{array}{l}\text { BMI } \\
\mathrm{n}=449,966(88.8 \%) \\
\text { missing=56,501 } \\
(11.2 \%)\end{array}$} & Underweight & 20.2 & 79.8 & 29.5 & 70.5 \\
\hline & Normal & 26.8 & 73.2 & 34.1 & 65.9 \\
\hline & Overweight & 23.1 & 76.9 & 28.3 & 71.7 \\
\hline & Obese & 17.3 & 82.7 & 19.9 & 80.1 \\
\hline \multirow{5}{*}{$\begin{array}{l}\text { Health Status } \\
\mathrm{n}=471,061(93 \%) \\
\text { missing=33,695 } \\
(6.7) \%\end{array}$} & Excellent & 38.5 & 61.5 & 40.0 & 60.0 \\
\hline & Very Good & 29.4 & 70.6 & 29.2 & 70.8 \\
\hline & Good & 21.6 & 78.4 & 21.1 & 78.9 \\
\hline & Fair & 17.0 & 83.0 & 15.4 & 84.6 \\
\hline & Poor & 14.4 & 85.6 & 13.6 & 86.4 \\
\hline
\end{tabular}

Note: Table includes some missing values due to responses that were missing, refused and unknown. MS recommendations included $2+$ times per week of exercises.

Table 2: Likelihood of Meeting MS Recommendations in a Nationwide Sample of 332,820 Adults Ages 45 years and Above 
Age, Disability, Muscle Strengthening Recommendations

\begin{tabular}{|c|c|c|}
\hline & Variable & Odds Ratios $(95 \% \mathrm{CI}) \Psi$ \\
\hline \multirow[t]{2}{*}{ Sex } & Male & $1.29(1.26-1.33)$ \\
\hline & Female & Ref \\
\hline \multirow[t]{2}{*}{ Age } & $45-64$ years & $1.18(1.15-1.21)$ \\
\hline & $65+$ & Ref \\
\hline \multirow[t]{2}{*}{ Disability } & Persons with Disability & $1.09(1.05-1.13)$ \\
\hline & Persons without Disability & Ref \\
\hline \multirow[t]{5}{*}{ Health Status } & Excellent & Ref \\
\hline & Very Good & $0.67(0.65-0.69)$ \\
\hline & Good & $0.49(0.47-0.51)$ \\
\hline & Fair & $0.38(0.36-0.41)$ \\
\hline & Poor & $0.32(0.28-0.36)$ \\
\hline \multirow[t]{2}{*}{ Chronic Disease } & Yes & $1.58(1.20-2.08)$ \\
\hline & No & Ref \\
\hline \multirow[t]{4}{*}{ BMI } & Underweight & $2.05(1.86-2.26)$ \\
\hline & Healthy weight & $1.97(1.90-2.05)$ \\
\hline & Overweight & $1.48(1.43-1.54)$ \\
\hline & Obese & Ref \\
\hline \multirow{4}{*}{ Education Level } & High School or less & $0.41(0.38-0.44)$ \\
\hline & High School Graduate & $0.51(0.50-0.53)$ \\
\hline & Attended College/Technical School & $0.71(0.69-0.73)$ \\
\hline & Graduated College/Technical School & Ref \\
\hline \multirow{4}{*}{ Race/Ethnicity } & White - Non-Hispanic & Ref \\
\hline & Black & $1.21(1.15-1.28)$ \\
\hline & Hispanic & $1.02(0.96-1.08)$ \\
\hline & Other & $1.05(0.98-1.12)$ \\
\hline
\end{tabular}

Persons were classified as persons with disability if they reported an activity limitation and that they used special equipment, such as a mobility aid. Those answering "no" to both questions were classified as persons without disability. BMI is defined as $\mathrm{kg} / \mathrm{m}^{2}$. Underweight: < 18.5; Normal: 18.5-24.9; Overweight: 25.0-29.9; Obese: $\geq 30$.

Table values are odds ratios. $\Psi$ 95\% Confidence Interval (CI) for OR was calculated from the standard error. Significant valued are bolded.

\begin{tabular}{|c|c|c|c|}
\hline \multicolumn{4}{|c|}{ Model Summary } \\
\hline \multirow{2}{*}{ Step } & -2 Log likelihood & Cox \& Snell R Square & Nagelkerke R Square \\
\hline 1 & $154167.503^{\mathrm{a}}$ & .060 & .087 \\
\hline
\end{tabular}

a. Estimation terminated at iteration number 5 because parameter estimates changed by less than .001 .

Table 3: Logistic Models Showing

Likelihood of Meeting MS by Disability Status in a Nationwide Sample of Adults Aged 45 Years and Above $(n=344,288)$ 
Age, Disability, Muscle Strengthening Recommendations

\begin{tabular}{|c|c|c|c|}
\hline & \multirow{3}{*}{$\begin{array}{c}\text { Disability } \\
\text { Odds Ratios }(95 \% \text { CI }) \Psi \\
\end{array}$} & \multirow{3}{*}{$\begin{array}{c}\text { No Disability } \\
\text { Odds Ratios }(95 \% \text { CI }) \Psi\end{array}$} \\
\hline & & & \\
\hline & Variable & & \\
\hline \multirow[t]{2}{*}{ Sex } & Male & $1.24(1.16-1.32)$ & $1.31(1.27-1.34)$ \\
\hline & Female & Ref & Ref \\
\hline \multirow[t]{2}{*}{ Age } & 45-64 years & $1.20(1.13-1.28)$ & $1.13(1.09-1.16)$ \\
\hline & $65+$ & Ref & Ref \\
\hline \multirow[t]{5}{*}{ Health Status } & Excellent & Ref & Ref \\
\hline & Very Good & $0.72(0.65-0.79)$ & $0.67(0.65-0.69)$ \\
\hline & Good & $0.54(0.49-0.60)$ & $0.48(0.46-0.50)$ \\
\hline & Fair & $0.43(0.38-0.48)$ & $0.37(0.34-0.40)$ \\
\hline & Poor & $0.36(0.31-0.42)$ & $0.31(0.25-0.40)$ \\
\hline \multirow{2}{*}{$\begin{array}{l}\text { Chronic } \\
\text { Disease }\end{array}$} & Yes & $0.63(0.47-0.84)$ & $1.27(0.46-3.48)$ \\
\hline & No & Ref & Ref \\
\hline \multirow[t]{4}{*}{ BMI } & Underweight & $1.46(1.17-1.82)$ & $2.26(2.02-2.52)$ \\
\hline & Healthy weight & $1.84(1.69-2.00)$ & $2.01(1.92-2.09)$ \\
\hline & Overweight & $1.50(1.38-1.63)$ & $1.48(1.42-1.55)$ \\
\hline & Obese & Ref & Ref \\
\hline \multirow{4}{*}{$\begin{array}{l}\text { Education } \\
\text { Level }\end{array}$} & High School or less & $0.36(0.31-0.42)$ & $0.43(0.40-0.46)$ \\
\hline & High School Graduate & $0.50(0.46-0.55)$ & $0.52(0.50-0.54)$ \\
\hline & Attended College/Technical School & $0.73(0.68-0.78)$ & $0.71(0.69-0.74)$ \\
\hline & Graduated College/Technical School & Ref & Ref \\
\hline \multirow{4}{*}{ Race/Ethnicity } & White - Non-Hispanic & Ref & Ref \\
\hline & Black & $1.00(0.87-1.16)$ & $1.25(1.18-1.33)$ \\
\hline & Hispanic & $0.93(0.79-1.09)$ & $1.03(0.97-1.10)$ \\
\hline & Other & $1.04(0.87-1.24)$ & $1.06(0.98-1.14)$ \\
\hline \multirow[t]{6}{*}{ Marital Status } & Married & Ref & Ref \\
\hline & Widowed & $0.97(089-1.05)$ & $1.07(1.033-1.12)$ \\
\hline & Divorced & $0.83(0.75-0.92)$ & $0.85(0.81-0.89)$ \\
\hline & Separated & $1.20(0.95-1.50)$ & $1.10(0.99-1.23)$ \\
\hline & Never Married & $1.00(0.90-1.11)$ & $0.98(093-1.03)$ \\
\hline & Member of unmarried couple & $0.99(0.79-1.26)$ & $1.08(0.97-1.20)$ \\
\hline
\end{tabular}

Persons were classified as persons with disability if they reported an activity limitation and that they used special equipment, such as a mobility aid. Those answering "no" to both questions were classified as persons without disability. BMI is defined as $\mathrm{kg} / \mathrm{m}^{2}$. Underweight: < 18.5; Normal: 18.5-24.9; Overweight: 25.0-29.9; Obese: $\geq 30$. 
Age, Disability, Muscle Strengthening Recommendations

Table values are odds ratios. $\Psi$ 95\% Confidence Interval (CI) for OR was calculated from the standard error. Significant valued are bolded.

\begin{tabular}{|l|r|r|c|}
\hline \multicolumn{4}{|c|}{ Model Summary $^{\mathbf{a}}$} \\
\hline Step & -2 Log likelihood & $\begin{array}{c}\text { Cox \& Snell R } \\
\text { Square }\end{array}$ & $\begin{array}{c}\text { Nagelkerke R } \\
\text { Square }\end{array}$ \\
\hline 1 & $128906.853^{\mathrm{b}}$ & .061 & .088 \\
\hline
\end{tabular}

a. Disability Category $=$ No Disability

b. Estimation terminated at iteration number 5 because

parameter estimates changed by less than .001 . 